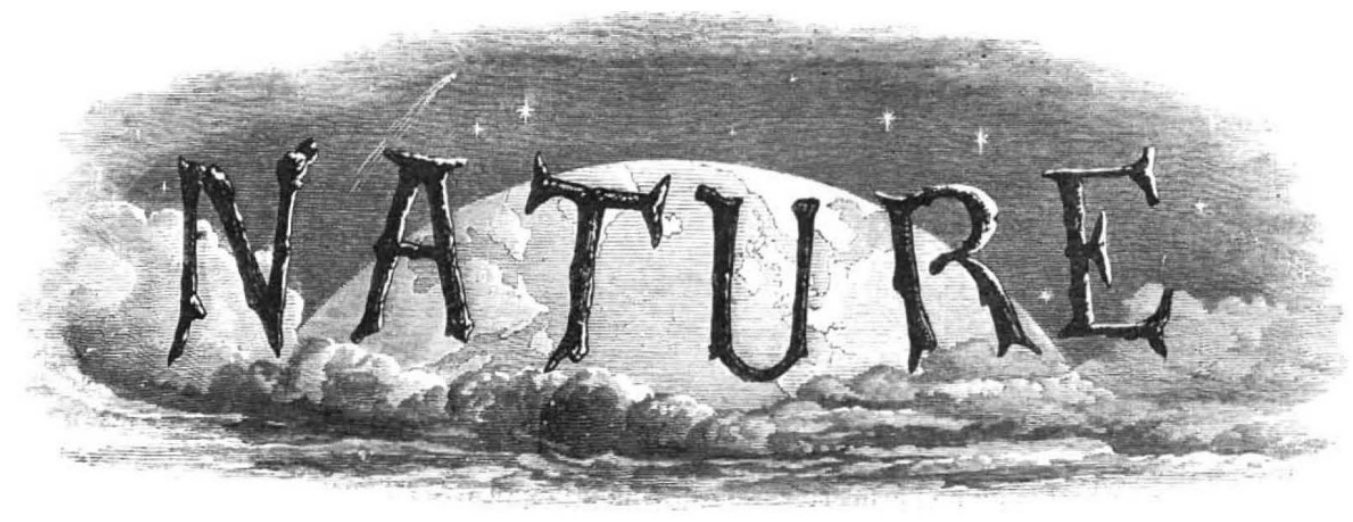

A WEEKLY ILLUSTRATED JOURNAL OF SCIENCE

"To the so'id ground

Of Nature trusts the mind which builds for aye."-WORDSWORTH

THURSDAY, MAY I, $\mathbf{1} 884$

\section{SCIENCE AND MANUFACTURES}

TH Iron and Steel Institute, and by the Institution of Mechanical Engineers, seems to offer a fitting occasion for further remarks on the connection between science and art, between practical construction and theoretical investigation. A few months ago, in an article on the same subject, it was pointed out how these two branches of knowledge were found to work in harmony for the ends of each-science instructing art, art supporting and ministering to science ; and this truth was illustrated by a variety of examples. Others which have occurred since that time may be touched upon before we conclude. At this moment we are anxious to insist once more on the need which exists to draw this union between art and science closer than it has ever been drawn before, and to remove all obstacles which may stand in the way of its fullest realisation.

The necessity for this union lies in the fact that England has an industrial supremacy to maintain, and that year by year its maintenance becomes more difficult in the face of keen and jealous competition. Whatever may be said in Parliament, all practical men are aware that the great tide of prosperity, promised last year by the President of the Board of Trade, has not yet begun to flow ; that on the contrary there was never perhaps a time when the special industries of England were more depressed, or their outlook more gloomy. The fact that the steel-rail makers of England have.banded themselves with those of France and Belgium into an association for the maintenance of remunerative prices speaks volumes, not only as to the severity of competition, but as to the sources from which that competition comes. On the other side we see the iron-masters of America extending their output year by year, and her manufacturers entering into competition with us in neutral markets, while jealously excluding us from their own.

What is to be the remedy for this state of things? How Vol. $\mathrm{xxx} .-$ No. 757 is the demand for manufactured articles, and for the raw materials out of which those articles are made, to be once more equalised with the supply? Unless some vast market, such as China or Central Africa, can be opened up to European commerce, the only chance seems to lie in a new departure ; in some great cheapening of production, or cheapening of transport, comparable to that which was effected by the development of railways. Now what is the physical fact lying at the basis of railway locomotion? It is simply this, that iron laid in the form of a track offers a resistance to rolling which, as compared with an ordinary road, is insignificant, whilst at the same time it offers a resistance to sliding large enough to utilise to the full the vast tractive power of the modern locomotive. The first point had long been known; the second was seized by the practical genius of George Stephenson, and enabled him at once to solve the problem of high speed locomotion. In so doing he owed nothing to science; but science might have discovered the fact, and would have done so with small trouble, if the idea had been put into her head-if, in fact, there had been in England that union of theory with practice which it is our present aim to advocate.

What is wanted now is that science shall point out some other fact of nature, new or old, which practice may seize upon, turn to her own ends, and make the basis of some new industrial development. It is easy to indicate various directions which such a development might take. Thus there is great need of some system of light railways which can be laid down on ordinary roads, and so cheaply that the traffic available on such roads may be sufficient to pay a fair return on the capital. It is impossible to calculate the advantages which would spring from the wide extension of such "third-class railways," as they are called in Germany. Again, the storage of power, such as that of the tidal wave, with cheap and ready means for giving it out when and where it is needed, offers a wide field for invention, and may lead to the most fruitful results. The transmission of power to long distances, whether by electricity, compressed air, or otherwise, is a somewhat similar problem, which at present occupies the attention of many engineers and men of science. Lastly, the more homely subject of house-building offers at this 
moment special inducements to constructive genius. If houses could be built, by the use of iron or otherwise, at, say, half their present cost, the problem of sheltering our poor would be solved; unsafe and ruinous tenements would disappear, and a demand would set in for building materials and labour such as the world has never known.

Here, however, the question arises, Supposing that science and art should combine successfully for any such purpose, is it in England that the development will take shape?

At the time of the last industrial epoch, that of the introduction of railways, it would have been safe to prophesy that this would be the case. It is by no means so certain now. As regards cheap transport, for instance, the most promising recent invention in this field, viz. the caustic soda condenser previously described by us, was brought out in Germany. Other improvements in the same field, such as the portable railways of De Cauville, the rack railway of Riggenbach, the cable tramway of Hallidie, the fireless engine of Francq, the iron sleepers which are rapidly becoming universal in Germany, have all taken their rise either on the Continent or in America. The storage of power, in its only practical form, that of the secondary battery, owes its origin to Planté and Faure. The transmission of power is being worked out by Siemens in Berlin, and by Deprez and Tresca in Paris. Lastly, as to building, no one can travel abroad without seeing that as regards scientific architecture, England stands far nearer the bottom than the top in the scale of civilised nations.

What is the reason of this? Why is England thus lagging behind in the race? The answer is not far to seek. In America, in France, above all in Germany, the union between science and art is far more close and corCial tnan with us. Every practical constructor or manufacturer is anxious to know all he can of science, every scientific professor desires to mix practice with his theory. Thus on the one hand we find ordinary engineers drawing on all the resources of mathematics for the solution of such problems as the proper section of rails or the resistance of trains; on the other hand we see Clausius, perhaps the greatest of German physicists, devoting two long papers to investigate the working theory of the dynamo machine. But a concrete instance will make our meaning clearer. Within the last few days we have inspected a safety lamp, of which some thousands have already been sold for the German mines. It has many points of excellence, but we need only dwell upon one. It is well known to be most important that a miner's lamp should be locked in such a way that he cannot, if he will, open it ; and it has been found very difficult to provide any simple kind of lock which it is beyond the resources of a clever workman to tamper with. In this lamp the difficulty is got over by making the upper part screw into the lower, while inside the lamp there is a catch or pawl, which, as in a common ratchet, prevents the screw from being turned the opposite way. Hence, that the lamp may be unscrewed, the pawl must be drawn out of place. In the overseer's office this can be accomplished by means of a powerful horse-shoe magnet. The pawl has a tail, which is attracted by the magnet when the latter is placed in contact with the side of the lamp. The tail moving towards the magnet, the pawl moves in the opposite direction, and so allows the upper part of the lamp to be unscrewed, while the lower is held as if in a vice by the same magnetic power.

Now here we have a simple and beautiful contrivance for effecting an important practical object. It is merely the application of a well-known scientific principle to solve a special problem in construction ; but it never could have been invented except by one to whom the resources of science and the nceds of art were equally familiar-who was at once a physicist and an engineer. Now it cannot be questioned that in England we can boast many of the highest authorities in science, many men of the highest skill in practical construction; but the union of the two is comparatively rare, and yet it is this very union-the application of the scientific spirit to the things of common life, as so well illustrated in the excellent paper by Prof. Newcomb, published elsewhere-which is the vital necessity of the age.

The fault is not all on one side. Science sometimes looks down on Practice as a rough, prosperous mechanic, interested in nothing but his work and his wages, while Practice sneers at Science as a fine gentleman, too much absorbed in crotchets to be worth any attention or respect, and who, if he had not some one to look after him, would shortly be in the workhouse.

As an instance we may take the magnetic balance lately described by Prof. Hughes. This beautiful instrument promises at least to supply a want long felt by the makers and users of iron-the want of some method of "mechanical analysis"-some means of determining the physical and chemical properties of a given materialwithout testing it to destruction, as is now unavoidable. But whilst thus appealing on the one hand to manufacturers, the invention appealed on the other hand to electricians, as offering a ready index of the magnetic qualities of a metal. By the latter it has been welcomed, and is being used, as, for instance, by Mr. Preece, for the testing of telegraph-wire; but, so far as we know, not a single manufacturer or engineer has thought it worth while to encounter the small amount of trouble and expense which would be needed to test thoroughly the capabilities of the instrument in determining the mechanical properties of finished iron or steel.

We by no means wish to imply that no progress is being made in the direction here pointed out. The work undertaken by the City and Guilds Institute, the foundation of scientific colleges, such as those at Birmingham, Sheffield, Leeds, Nottingham, and elsewhere, the appointment of a Committee on Technical Education, the delivery of scientific lectures at the Institution of Civil Engineersthese are all signs that the gap existing between art and science is at last recognised, and that endeavours are being made to draw them together. Moreover, the old "rule-of-thumb" engineer is rapidly passing away, and a new generation is springing up, who, if they do not possess much science themselves, are at least alive to its value. The testing machine, for instance, is becoming a recognised institution in large workshops, where not many years ago it would have been scouted as absurd. In the skilful hands of a practical engineer, Mr. Wicksteed of Leeds, it has been made to record its own variations of stress by a self-drawn diagram, and this record seems likely to throw fresh and unexpected light on the physical 
problems of extension and rupture. The same gentleman has both discovered and applied a new and most remarkable phenomenon in friction; the fact, namely, that if we give a rotary motion to a body which is in contact with another, not only is the friction diminished in the direction of motion, but the friction in the perpendicular direction is also diminished, apparently in at least an equal degree. Hence, for instance, by rotating the leather packing of an hydraulic ram, it becomes quite free to move in its cylinder in obedience to a difference in pressure on one side or the other. Here we have, once more, science hclping. art, and art in return throwing light upon the path of science.

These facts, and others like them, are encouraging signs, but we must repeat that something more than signs is needed. The work must be not only begun but finished, the bonds of union must be drawn close, and that quickly, or England will find that it is too late, and that she is once more ready to do the work of the world just when the world has left her no work to do.

FORSTER'S "STRATA OF THE NORTH OF ENGLAND"

A Treatise on a Section of the Strata from Nevucastle to Cross Fell. By Westgarth Forster. Third Edition, revised and corrected to the present time by the Rev. W. Nall, M.A., with Memoir. 8vo. (Newcastle-uponTyne, I883.)

THE position of Forster's "Strata" among the classics of geological literature in England is so well defined that a reissue would be welcome to many readers, as although the progress both of coal and metal mining during the long interval that has elapsed since the appearance of the last edition in I82I has done much to supplement, and in some instances modify, the author's evidence, it must ever remain as a splendid monument of geological investigation as carried on in the earlier years of the century. Unfortunately, in the present issue the editor has carried out his duties in a very thorough-going fashion; to use his own words, "Some alterations have been made in this edition of the 'Strata.' Parts I. and II. have been revised and rearranged; Part III. has been partially recast; some of the old sections have been extended, and other sections have been given; obsolete matter has been expunged, and new matter in the form of notes has been added."

If the editing had been confined to the last-mentioned additions, or rather if all the alterations had been supplied as footnotes or in the form of appendixes, such a course would have been perfectly justifiable, and the value of the text would have been enhanced; but from the course adopted of shifting the original text backwards and forwards to bring it into harmony with more modern views, and rearranging the sections even to the extent of renumbering the beds of limestone in the lead-measures, and the intercalation of new subdivisions in the limestone series not contained in the original, the work has become so strangely metamorphosed that any one taking it for what it professes to be, namely, Westgarth Forster's "Strata," will be liable to be strangely misled, unless he carefully compares it with the original text. This is much to be regretted, as the editor's work has evidently been a labour of love, and it is strange that he should have so ill-used his favourite volume.
The editor has, however, done one good service deserving grateful mention by supplying a memoir of the author, which is, howcver, eccentrically interpolated between the original table of contents and the text. From this we gather many interesting particulars of the life of one who may be regarded as the prototype of the Sopwiths, Bewicks, and other mining engineers in the north of England, who have become famous not only in their original districts, but in all parts of Europe and America It is somewhat surprising to learn how in the year 1807 the material for the first edition of the "Strata" was collected by Forster, who for that purpose resigned the agency of the Allendale lead mines. The volume was issued in 1809 in the same year with William Smith's first geological map of England, and at once became exceedingly popular; and thenceforward the author was recognised as one of the leading men in his profession, and was fully engaged in many surveys until his retirement in 1833 . During this active period of twenty-three years he worked in nearly all the mineral districts of England and Wales, with the exception of Cornwall and Devon, and also visited Spain and North America. The American trip was made in 1831 , in pre-steamboat days, in the fine packetship Napoleon, making a fairly good voyage of thirty-two days across the Atlantic. The districts visited were Pottsville and Mauch Chunk, in the anthracite district of Pennsylvania, which had then been discovered only eight years, and the Phœnix Copper Mines in Connecticut.

The later years of his life were clouded by misfortunes due to losses in working some lead mines in Wales, and before the spring of 1829 he had spent nearly all that he possessed in abortive trials, at a period of extreme depression in the lead trade. In $1833-34$ failing health led him to retire from active work, and on November 9, 1835 , he died at Garrigill, in Cumberland, in his sixty-third year. In the author's words, Forster rendered valuable service to the sciences of mining and geology, and for that service, if for no other reason, his name will continue to be remembered for a long time to come.

H. B.

\section{OUR BOOK SHELF}

\section{A Manual of Chemistry. By Henry Watts, B.A. (London:} Churchill, r883.)

THIS work is stated by the author to be intended for a student commencing the study of chemistry, and, as he states in his preface, this volume commences with a short sketch of the more important elementary bodies, the principal laws of chemical combination, and the representation of the constitution and reaction of bodies by symbolic notation. In addition to this there is a large section on chemical physics, including the mechanical properties of gases and the chief phenomena of heat, light, magnetism, \&c. For an elementary work, as intended by the author, it is somewhat dense, and would be certainly apt to frighten a beginner in chemistry. The sections on physics alone, comprising Part I., occupy very nearly 150 pages, and within this narrow space we find that in the domain of light we have refraction, reflection, circular polarisation, \&c., treated at considerable length. In magnetism and electricity we have a very complete and exceedingly condensed mass of information, certainly much too complete and condensed for an elementary text-book. In the purely chemical section, forming Part II., the work is extended so as to include a considerable chapter on crystals and the more recent extensions of the atomic theory, and also to the so-called rare metals, 